\title{
Electrocardiogram Abnormality Associated with Methadone Overdose
}

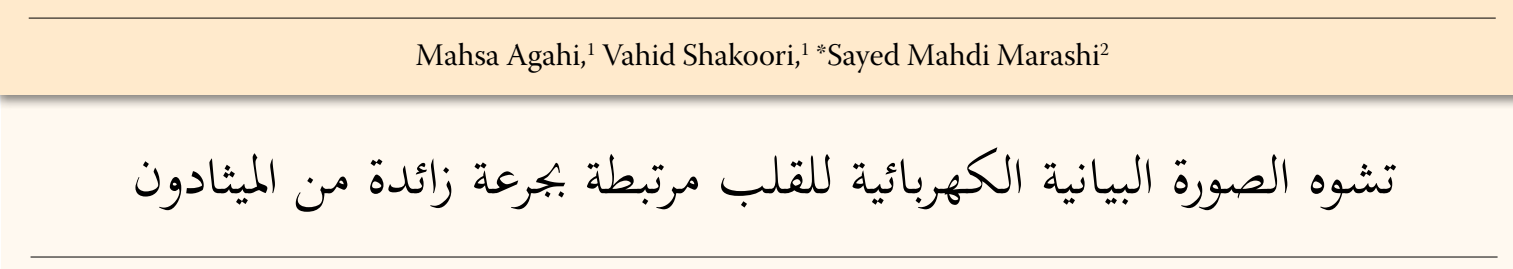

$$
\text { مهسا آكاهي، وحيد شكوري، سيد مهدي مرعشي }
$$
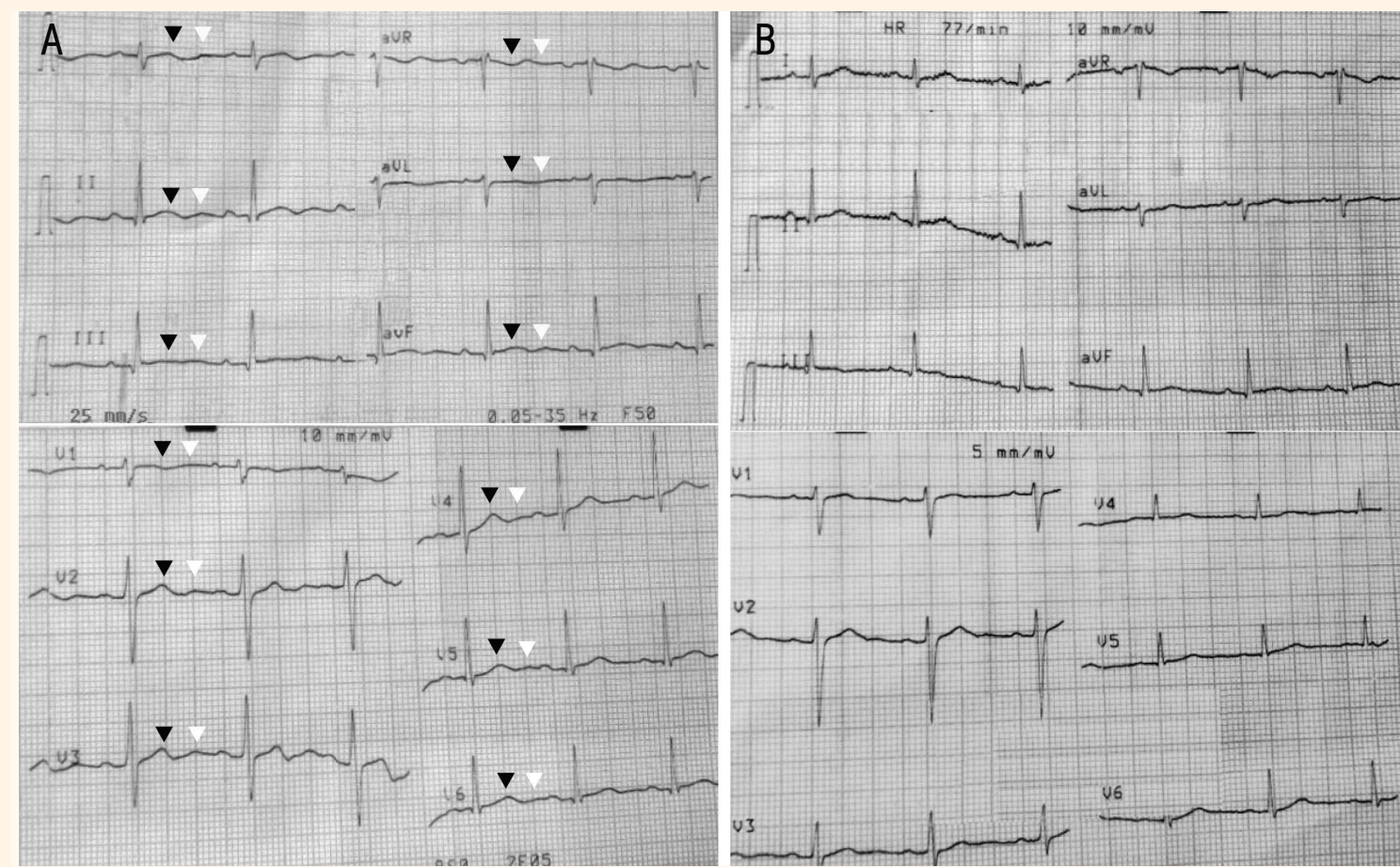

Figure 1A \& B: 12-lead electrocardiograms (ECGs) in a patient with methadone intoxication (A) within the first hour of admission showing $\mathrm{T}$ (black arrowheads) and $\mathrm{U}$ (white arrowheads) waves and (B) 48 hours later. Note the complete normalisation of the abnormalities in the second ECG which occurred without the use of antiarrhythmic agents.

A 19-YEAR-OLD MALE PATIENT PRESENTED to the Emergency Department at Hazrat-e Ali Asghar Hospital, Shiraz, Iran, in May 2015 four hours after ingesting $200 \mathrm{mg}$ of methadone in a suicide attempt. His past medical and family history were negative for any hereditary diseases. He had a history of opium addiction but had been abstinent for the preceding six months; he had previously been prescribed $40 \mathrm{mg}$ of methadone per day as treatment for his opiate dependence. On examination, the patient was conscious, well-oriented and had stable vital signs. Laboratory tests and arterial blood gas analysis were within normal limits.
A 12-lead electrocardiogram (ECG) was performed [Figure 1A]. Although the ECG initially seemed normal, further inspection revealed that the QTC interval in the patient was approximately 500 milliseconds (ms). Moreover, the PR interval exceeded $200 \mathrm{~ms}$ and a small deflection after the $\mathrm{T}$ wave (known as the $U$ wave) was detected. Interestingly, another ECG performed 48 hours later, just before the patient was discharged, revealed the complete normalisation of these abnormalities without the administration of antiarrhythmic agents [Figure 1B]. 


\section{Comment}

Acquired long QTc intervals are associated with the use of certain medications, including antihistamines, class I and class III antiarrhythmics, antidepressants, antipsychotics, antibiotics and antifungals. ${ }^{1}$ Genetic factors, the co-administration of the aforementioned drugs or hepatic enzyme inhibitors can also increase the risk of developing a long QTc interval. ${ }^{1}$ Methadone is a long-acting opioid usually prescribed for opiate withdrawal or as an analgaesic for patients suffering from side-effects due to narcotics. Methadone exerts its effects through $\mu$-opioid receptors and has an antagonistic effect on $\mathrm{N}$-methyl-D-aspartate receptors which results in the relief of neuropathic pain. Considering its long half-life, methadone is considered an optimal medication for chronic pain management in opioid-tolerant cancer patients. ${ }^{2}$

Despite being in use for more than 40 years, the cardiovascular effects of methadone have only recently been identified., ${ }^{2,3}$ Methadone use, either chronic use or an acute increase in dosage, leads to the blockage of the voltage-activated delayed potassium current (the IK channel) and causes prolonged repolarisation of the ventricular myocardium. As a result, methadone use is associated with prolonged QTc intervals on ECGs. ${ }^{1,3}$ Moreover, interruption of the repolarisation causes a decrease in the charge difference across the myocardial cell membrane, resulting in early postdepolarisation; thus, signifying an association with the U wave. ${ }^{1}$ As the prominent $U$ wave and prolonged QTC interval are signs of early post-depolarisation, doctors should be wary of triggering polymorphic ventricular tachycardia (also known as torsade de pointes). This is especially important when the QTc interval is more than $500 \mathrm{~ms}$, as this may adversely lead to syncope or sudden cardiac death. ${ }^{1,4}$

Patients who have been prescribed methadone should be assessed in order to identify those who are at potential risk of QTc interval prolongation. Baseline ECGs before treatment and routine ECGs on a biannual basis and upon hospital admission are recommended. ${ }^{5}$ Furthermore, as an acute increase in methadone dosage induces prolongation of the QTC interval, a 12-lead ECG should be considered during routine evaluation of these patients. Moreover, close inspection of the ECG is necessary, as prolonged QTC intervals may lead to severe complications.

\section{References}

1. Lionte $\mathrm{C}$, Bologa $\mathrm{C}$, Sorodoc L. Toxic and drug-induced changes of the electrocardiogram. In: Millis RM, Ed. Advances in Electrocardiograms: Clinical Applications. 1st ed. Rijeka, Croatia: InTech, 2012. Pp. 271-96. doi: 10.5772/22891.

2. Brown R, Kraus C, Fleming M, Reddy S. Methadone: Applied pharmacology and use as adjunctive treatment in chronic pain. Postgrad Med J 2004; 80:654-9. doi: 10.1136/pgmj.2004.022988.

3. Krantz MJ, Lewkowiez L, Hays H, Woodroffe MA, Robertson AD, Mehler PS. Torsade de pointes associated with veryhigh-dose methadone. Ann Intern Med 2002; 137:501-4. doi: 10.7326/0003-4819-137-6-200209170-00010.

4. Roden DM. Drug-induced prolongation of the QT interval N Engl J Med 2004; 350:1013-22. doi: 10.1056/NEJMra032426.

5. D'Arcy Y. Compact Clinical Guide to Acute Pain Management: An Evidence-Based Approach for Nurses. 1st ed. New York, USA: Springer Publishing Company, 2011. P. 211. 